\title{
Feco-prevalence and risk factors of Helicobacter pylori infection among symptomatic patients at Dessie Referral Hospital, Ethiopia
}

Abdurahaman Seid ${ }^{*}$ and Wondmagegn Demsiss

\begin{abstract}
Background: Helicobacter pylori (H. pylori) infection is the most common chronic bacterial infection in the world. It can result in various upper gastroduodenal diseases. The prevalence varies among countries, population groups within the same country and testing methods. The aim of the study was to determine feco-prevalence and risk factors of H.pylori infection among symptomatic patients in Amhara region, Northeast Ethiopia.

Methods: A cross sectional study was conducted in a total of 342 new consecutive outpatients with upper abdominal complaints at Dessie Referral Hospital from May to July, 2016. A structured questionnaire was used to collect the sociodemographic, lifestyle and environmental data. Stool samples were used to detect H. pylori specific antigen. Blood samples were assessed for anti-H. pylori lgG and ABO blood types. SPSS version 20.0 statistical software package was used for data analysis. Chi-square test and logistic regression were used in the analysis and $P$-value $\leq 0.05$ was considered as statistically significant.

Results: H. pylori stool antigen and serum anti-H.pylori lgG detection rate was 30.4 and $60.5 \%$ respectively with kappa measure of agreement of 0.271 . Antigen detection was significantly associated with family size (>3) [AOR $=1.83,95 \%$ $\mathrm{Cl}: 1.10-3.05, p=0.02]$, more persons ( $>3$ ) sharing the same bed room in the household [AOR $=2.91,95 \%$ Cl: 1.39-6.11, $p=0.005]$, alcohol consumption ( $>$ once a week) $[\mathrm{AOR}=2.70,95 \% \mathrm{Cl}: 1.49-4.89, p=0.001]$ and individuals' blood type: group $\mathrm{O}[\mathrm{AOR}=8.93,95 \% \mathrm{Cl}: 1.79-44.48, p=0.008]$ and group $\mathrm{A}[\mathrm{AOR}=5.53,95 \% \mathrm{Cl}: 1.08-28.36, p=0.040]$. Gender, age, marital status, occupation, educational level, residence, smoking as well as coffee, tea, fruits and vegetables consumption were not statistically associated with $H$. pylori antigen detection ( $p>0.05)$.

Conclusion: The overall H. pylori stool antigen and anti-H. pylori lgG detection rate was 30.4 and $60.5 \%$, respectively. The test agreement was not strongly convincing and needs further evaluation. Alcohol consumption, overcrowding and ABO blood group were significantly associated with $H$. pylori antigen detection.
\end{abstract}

Keywords: H. pylori, Stool antigen, Serum lgG, Risk factors, Ethiopia

\footnotetext{
* Correspondence: nebat_abdurae2003@yahoo.com; gechdk2000@yahoo.com

Department of Medical Laboratory Science, College of Medicine and Health

Sciences, Wollo University, P.O. Box 1145, Dessie, Ethiopia
}

(c) The Author(s). 2018 Open Access This article is distributed under the terms of the Creative Commons Attribution 4.0 International License (http://creativecommons.org/licenses/by/4.0/), which permits unrestricted use, distribution, and reproduction in any medium, provided you give appropriate credit to the original author(s) and the source, provide a link to the Creative Commons license, and indicate if changes were made. The Creative Commons Public Domain Dedication waiver (http://creativecommons.org/publicdomain/zero/1.0/) applies to the data made available in this article, unless otherwise stated. 


\section{Background}

H. pylori infects about half of the worlds' population with higher prevalence in developing than developed countries [1-3]. The prevalence of H.pylori infection varies among societies and geographical locations, and is influenced by different factors like environmental factors, socio-demographic characteristics, socioeconomic status, hygienic practice and life style of the population $[1,2,4]$. $H$. pylori infection occurs with an exposure to the bacterium through oral-oral and fecal-oral route $[4,5]$, but the fecal-oral route was identified to be the most important route of transmission [4].

Besides large numbers of infected individuals remained as asymptomatic [6], H. pylori infection is a major public-health problem both in developed and developing nations. It is the leading cause of different types of upper gastroduodenal tract diseases such as gastric and duodenal ulcer, gastritis and Mucosal-Associated Lymphoid Tissue (MALT) lymphoma [3, 7]. It is also responsible for the development of gastric cancer [8] which is the second leading cause of cancer-related deaths worldwide [9].

Early detection of $H$. pylori infection using a reliable diagnostic method is important for the successful management and prevention of disease complications. Since the discovery of $H$. pylori, both invasive and noninvasive tests are used for the diagnosis of infection. Histology, culture, polymerase chain reaction (PCR) and rapid urease test (RUT) are invasive tests that 'require biopsy specimens [10], whereas stool antigen test, Urea Breath Test (UBT) and serology are the most commonly used noninvasive tests $[11,12]$.

Even though a variety of diagnostic methods are available, only tests with sensitivity and specificity exceeding 90\% are recommended for clinical practice [13]. Even though serology is most commonly used in developing countries it is not appropriate for the diagnosis of active $H$. pylori infection. This is due to its low specificity (79-83\%), and presence of high titer of IgG for years after eradication of infection. This limits its importance to differentiate past and current exposure to $H$. pylori $[2,14]$. However, the UBT and $H$. pylori stool antigen (HpSA) test are a reliable noninvasive method for detection of active and recent $H$. pylori infection $[15,16]$. In the absence of UBT, the HpSA test is usually recommended for diagnosis of $H$. pylori infection [17] with a globally observed sensitivity and specificity of 94 and $97 \%$, respectively [18].

Most previous Ethiopian studies employed serology for diagnosis of $H$. pylori infection and reported higher seroprevalence of $H$. pylori infection. It is documented that besides lack of specificity, serological test cannot differentiate past and current infection. This puts a major limitation to know the actual incidence and real association of $H$. pylori infection with potential risk factors. Some studies conducted in the Southern and Central part of
Ethiopia reported the feco-prevalence and possible risk factors of $H$. pylori infection [19-22]. However, the reports lack consistency in prevalence and associated factors of H.pylori infection. This needs additional studies in order to document local burden of $H$. pylori infection and its associated risk factors.

Furthermore, feco-prevalence of $H$. pylori infection was not documented in the Amhara region of the country, which is quite different in socio-cultural properties of the population, environmental and geographical characteristics as compared to Southern and Central regions of the country. These factors may have an impact on the epidemiology of the disease. Currently, serology is the most commonly used rapid test algorithm for diagnosis of H.pylori infection in Ethiopia. It is valuable for each locality and region to determine the prevalence, identify risk factors associated with the infection and document the role of stool antigen test in comparison to commonly used rapid serologic test. Therefore, the aim of this study was to determine feco-prevalence and risk factors of $H$. pylori infection among patients with upper abdominal complaints. It also aimed to compare a rapid stool antigen and serologic test for the diagnosis of $H$. pylori infection.

\section{Methods}

\section{Study area}

The study was conducted at Dessie Referral Hospital, Dessie town, Amhara Region, North East Ethiopia. Dessie is located about $400 \mathrm{~km}$ from the capital of Ethiopia, Addis Ababa. Dessie Referral Hospital is the largest public hospital in the town. Patients with clinical indications of $H$. pylori infection are routinely tested in the hospital using rapid serological diagnostic tests.

\section{Study design and period}

A cross-sectional study was conducted from May to July, 2016.

\section{Sample size and sampling technique}

The sample size was determined by using single population proportion formula taking $72.2 \%$ prevalence of $H$. pylori infection among dyspeptic patients [23] with a marginal error of 5, and 95\% confidence interval. Accordingly, the total sample size was determined to be 339 with $10 \%$ non-response rate. However, during the study period 342 new patients with clinical indications of $H$. pylori infection were examined at the outpatient department of the hospital and included consecutively. All patients who presented with recurrent upper gastro-intestinal tract symptoms of more than one-month duration were included in the study. Patients treated with any antibiotics, colloidal bismuth compounds, proton pump inhibitors (PPI) or H2 blockers within the last 4 weeks of study enrolment were excluded. 


\section{Data collection and laboratory methods Questionnaires}

A structured and pre-tested "Amharic version" (local language) questionnaire was used for data collection. Prior to data collection the questionnaire was administered to 15 participants with upper gastrointestinal symptomatic patients to assess the clarity and understandability of questions. The questionnaire was administered for each adult participant/children guardian to collect information on the socio-demographic characteristic, hygienic practices and lifestyle factors such as alcohol, tea, coffee, raw fruits and vegetables consumption as well as cigarette smoking. For participants who can't read and write, interview was employed.

\section{Clinical sample collection and analysis $A B O$ blood grouping and serological detection of $\mathrm{H}$. pylori} About $5 \mathrm{ml}$ of venous blood was collected from each participant aseptically through venipuncture and AntiH. pylori antibody (IgG) detection as well as ABO blood grouping was made. Immediately after collection some portion of whole blood was used to determine $\mathrm{ABO}$ and Rh blood group by slide agglutination test using monoclonal anti-A, anti-B, anti-AB and anti-D (Rh) antibodies according to manufacturer's recommendation. Some portion of collected blood was allowed to clot in a test tube and centrifuged at 3000 RPM for $10 \mathrm{~min}$ and serum was separated. The antibody was detected by one-step rapid test device (Zhejiang Orient Gene Biotech Co., LTD, china; http://www.orientgene.com/asp-en/home/ index.aspx). The appearance of color band on both test and control line was interpreted as positive but color band only on the control line is interpreted as negative result. All tests were performed following the manufacturer's instructions.

\section{H. pylori antigen detection}

Small amount of fresh stool sample was collected from each participant in sterile, wide mouth and screw caped containers. The presence of $H$. pylori antigen was determined using monoclonal anti-H. pylori antibody conjugated with colloid gold nitrocellulose membrane strip (Rapid stool antigen test) based on a lateral flow chromatographic immunoassay technique. Specimens were tested using stool antigen test strip (Guangzhou Wondfo Biotech CO., Ltd., China; https://www.bloomberg.com/research/stocks/ private) with sensitivity and specificity of 99.1 and $99.2 \%$, respectively. Test results were read and interpreted according to the manufacturer's instructions.

\section{Data analysis}

Data was coded, entered and analyzed using SPSS Version-20 (SPSS INC, Chicago, IL, USA). Results were summarized using descriptive statistics. Cohen's Kappa statistics was performed to assess the agreement of rapid serological test (anti-H. pylori IgG) and rapid stool antigen detection. Chi-square test and binary logistic regression analysis were performed to check the presence of association between dependent variable (presence of $H$. pylori antigen) and independent variables. Furthermore, possible risk factors with a $P$ value of $<0.2$ in univeriate analysis were selected for further stepwise analysis with multiple logistic regression model. The OR and 95\% confidence interval (CI) were used to estimate the risk factors independently associated of $H$. pylori infection. Finally, a $P$ value of $\leq 0.05$ was accepted as statistically significant.

\section{Results}

Socio-demographic, lifestyle and hygienic characteristic of study participants

Out of 342 participants, 189 (55.3\%) were females. Majority of study participants 114 (33.3\%) were in the age group 31-40 years. The mean $( \pm S D)$ age of participants was $36.61 \pm 13.2$ years with range 4 to 77 years. Majority of participants 218 (63.7\%) were married and urban dwellers account 210 (61.4\%). One hundred sixty-seven (48.8\%) participants were living in a family having four or more members (Table 1).

An assessment on the food habits of the study participants revealed that 67.8 and $61.7 \%$ had a habit of tea and coffee consumption respectively; $53.5 \%$ had never drank alcohol in their life and $58.8 \%$ had a habit of eating raw fruits and/or vegetables at least once a week. About 94.2\% (322) of participants had a habit of hand washing before eating and after visiting toilet; 282 (82.5\%) used tap water for daily consumption. The frequency of blood group $\mathrm{O}$ was 137 (40.1\%) and 326 (95.3\%) were with rhesus positive $(\mathrm{Rh}+\mathrm{ve})$ blood type (Table 2$)$.

\section{Prevalence of $H$. pylori infection}

$\mathrm{HpSA}$ and Anti-H.pylori IgG detection rate were 30.4 and 60.5\%, respectively. Eighty-eight (25.7\%) and 119 (34.8\%) participants were positive and negative for both tests, respectively. Kappa measures of agreement between results of HpSA testing and IgG antibody serology was $0.271(p<0.0001,95 \%$ CI: $0.191-0.351)$, but it was not strongly convincing since discordant results were observed for 135 individuals (39.5\%): 16 (4.7\%) were positive on HpSA test but negative by serology and 119 (34.8\%) were IgG seropositive but had negative HpSA tests.

\section{Socio-demographic characteristics and feco-prevalence of H. pylori infection}

Pearson's chi-square test showed that HpSA detection was significantly associated with number of persons sharing the same bedroom in the family $\left(\chi^{2}=10.14, p=\right.$ $0.006)$ and family size in the household ( $\chi^{2}=8.25, p=$ 
Table 1 Feco-prevalence of $H$. pylori infection against socio demographic, characteristics of symptomatic patients in Dessie Referral Hospital, Northeast Ethiopia, $2016(n=342)$

\begin{tabular}{|c|c|c|c|c|c|}
\hline \multirow[t]{2}{*}{ Variables } & & \multirow[t]{2}{*}{ freq $(\%)$} & \multicolumn{3}{|l|}{$\operatorname{HpSA}(+)$} \\
\hline & & & No (\%) & $x^{2}$ & $p$-value \\
\hline \multirow[t]{2}{*}{ Sex } & Male & $153(44.7)$ & $43(28.1)$ & 0.70 & 0.404 \\
\hline & Female & $189(55.3)$ & $61(32.3)$ & & \\
\hline \multirow[t]{5}{*}{ Age in years } & $\leq 20$ & $30(8.7)$ & $7(23.3)$ & 1.60 & 0.809 \\
\hline & $21-30$ & 94 (27.5) & $26(27.7)$ & & \\
\hline & $31-40$ & $114(33.3)$ & $38(33.3)$ & & \\
\hline & $41-50$ & $53(15.5)$ & $17(32.1)$ & & \\
\hline & $>50$ & $51(14.9)$ & $16(31.4)$ & & \\
\hline \multirow[t]{2}{*}{ Marital status } & Married & $218(63.7)$ & 65 (29.8) & 0.1 & 0.752 \\
\hline & Not married & $124(36.3)$ & $39(31.5)$ & & \\
\hline \multirow[t]{2}{*}{ Residence } & Rural & 132 (38.6) & $41(31.1)$ & 0.04 & 0.836 \\
\hline & Urban & $210(61.4)$ & $63(30)$ & & \\
\hline \multirow[t]{6}{*}{ Occupation } & Government & $111(32.5)$ & $32(28.8)$ & 1.40 & 0.924 \\
\hline & Student & $45(13.2)$ & $15(33.3)$ & & \\
\hline & Farmer & $69(20.2)$ & $24(34.8)$ & & \\
\hline & Merchant & $51(14.9)$ & $15(29.4)$ & & \\
\hline & Housewife & $53(15.5)$ & $15(28.3)$ & & \\
\hline & Others & $13(3.8)$ & $3(23.1)$ & & \\
\hline \multirow[t]{5}{*}{ Education } & No legal education & $53(15.5)$ & $18(34.0)$ & 4.31 & 0.366 \\
\hline & Grade 1-4 & $28(8.2)$ & $10(35.7)$ & & \\
\hline & Grade 5-8 & $58(17.0)$ & $15(25.9)$ & & \\
\hline & Grade9-12 & $78(22.8)$ & $29(37.2)$ & & \\
\hline & College/university & $125(36.5)$ & 32 (25.6) & & \\
\hline \multirow[t]{3}{*}{ Person sharing the same bed room in the household } & 1 & $77(22.5)$ & $18(23.4)$ & 10.14 & $0.006^{*}$ \\
\hline & 2 to 3 & $181(52.9)$ & $49(27.1)$ & & \\
\hline & $>3$ & $84(24.6)$ & $37(44.0)$ & & \\
\hline \multirow[t]{2}{*}{ Family size } & $1-3$ & $175(51.2)$ & $41(23.4)$ & 8.25 & $0.004^{*}$ \\
\hline & $>3$ & $167(48.8$ & $63(37.7)$ & & \\
\hline
\end{tabular}

Key: ${ }^{*}=$ Significant associations exist

0.004). However, other socio-demographic variables did not show any association $(P>0.05)$ (Table 2$)$.

\section{HpSA detection with respect to genetic, hygiene condition and lifestyle factors}

Pearson's chi-square test revealed that hand washing after visiting toilet ( $\mathrm{X} 2=3.85, P=0.05)$, ABO blood phenotype $\left(x^{2}=10.35, p=0.016\right)$, alcohol drinking $\left(\chi^{2}=6.26, p=0.04\right)$ and raw fruits and/or vegetables $\left(\mathrm{X}^{2}=7.06, p=0.029\right)$ eating showed statistically significant association with HpSA detection.

Clearing the possible confounders, multiple logistic regression analysis showed that $\mathrm{HpSA}$ detection was significantly associated with $\mathrm{ABO}$ blood group type $\mathrm{O}$ $[\mathrm{AOR}=8.93,95 \% \mathrm{CI}: 1.79-44.48, p=0.008]$ and type A
[AOR $=5.53,95 \% \mathrm{CI}: 1.08-28.36, p=0.040]$; overcrowding: family size greater than three $[\mathrm{AOR}=1.83,95 \% \mathrm{CI}: 1.10$ $3.05, p=0.02]$ and greater than three persons sharing the same bed room in the family $[\mathrm{AOR}=2.91,95 \% \mathrm{CI}$ : 1.39 6.11, $p=0.005$ ]. A multivariate analysis also clearly noted that alcohol consumption greater than once a week can increase the risk of $H$. pylori infection by 2.7 times as compared to those who had never drank alcohol $[\mathrm{AOR}=2.70$, 95\% CI: $1.49-4.89, p=0.001]$. However, other variables as shown in Table 3 didn't show any association with antigen detection.

\section{Discussion}

H. pylori infection is an important public health issue globally with high prevalence among developing countries 
Table 2 Association of HpSA detection with respect to genetic, hygiene and lifestyle factors of symptomatic patients in Dessie Referral Hospital, Northeast Ethiopia, $2016(n=342)$

\begin{tabular}{|c|c|c|c|c|c|}
\hline \multirow[t]{2}{*}{ Variables } & & \multirow[t]{2}{*}{ Freq (\%) } & $\mathrm{HpSA}(+)$ & \multirow[t]{2}{*}{$x^{2}$} & \multirow[t]{2}{*}{$p$-value } \\
\hline & & & $=\mathrm{no}(\%)$ & & \\
\hline \multirow[t]{3}{*}{ Alcohol drinking } & Never & $183(53.5)$ & $48(26.2)$ & 6.26 & $0.044^{*}$ \\
\hline & Once a week & $71(20.7)$ & $20(28.2)$ & & \\
\hline & >Once a week & $88(25.7)$ & $36(40.9)$ & & \\
\hline \multirow[t]{3}{*}{ Raw fruit and vegetable eating } & Never & $85(24.9)$ & $29(34.1)$ & 7.06 & $0.029^{*}$ \\
\hline & At least once a day & $56(16.4)$ & $24(42.9)$ & & \\
\hline & At least once a week & $201(58.8)$ & $51(25.4)$ & & \\
\hline \multirow[t]{2}{*}{ Drinking water source } & Tap water & $282(82.5)$ & $86(30.5)$ & 0.01 & 0.939 \\
\hline & Non-tap water & $60(17.5)$ & $18(30.0)$ & & \\
\hline \multirow[t]{2}{*}{ Hand washing before eating } & Yes & $322(94.2)$ & $97(30.1)$ & 0.21 & 0.646 \\
\hline & No & $20(5.8)$ & $7(35.0)$ & & \\
\hline \multirow[t]{2}{*}{ Hand washing after toilet } & Yes & $322(94.2)$ & $94(29.2)$ & 3.85 & $0.050^{*}$ \\
\hline & No & $20(5.8)$ & $10(50.0)$ & & \\
\hline \multirow[t]{2}{*}{ Cigarette smoking } & Yes & $18(5.3)$ & $4(22.2)$ & 0.60 & 0.438 \\
\hline & Never & $324(94.7)$ & $100(30.9)$ & & \\
\hline \multirow[t]{2}{*}{ Tea consumption } & Yes & $232(67.8)$ & $65(28.0)$ & 1.95 & 0.163 \\
\hline & No & $110(32.2)$ & $39(35.5)$ & & \\
\hline \multirow[t]{2}{*}{ Coffee consumption } & Yes & $211(61.7)$ & 70 (33.2) & 1.99 & 0.158 \\
\hline & No & $131(38.3)$ & $34(26.0)$ & & \\
\hline \multirow[t]{4}{*}{ ABO Blood group } & Type A & $87(25.4)$ & $24(27.6)$ & 10.35 & $0.016^{*}$ \\
\hline & Type B & $96(28.1)$ & $25(26.0)$ & & \\
\hline & Type O & $137(40.1)$ & $53(38.7)$ & & \\
\hline & Type AB & $22(6.4)$ & $2(9.1)$ & & \\
\hline \multirow[t]{2}{*}{ Rhesus (Rh) } & $\mathrm{Rh}+\mathrm{ve}$ & $326(95.3)$ & $96(29.4)$ & 3.04 & 0.081 \\
\hline & Rh-ve & $16(4.7)$ & $8(50.0)$ & & \\
\hline
\end{tabular}

Key: ${ }^{*}=$ Significant associations exist

[1-3]. In this study the overall stool antigen and serum IgG detection rate of $H$. pylori infection was 30.4 and $60.5 \%$ respectively. Antigen detection rate is comparable with the work of Alim et al. 29.6\% [24] and Balan et al. $28.4 \%$ [25]. However, a lower prevalence rate was reported from Pakistan 25\% [26] and a higher prevalence rate was documented in Turkey 36.6\% [27], Japan 56.4\% [28], Iran (53.5\%) [29] and Ethiopia 50.7-58.3\% [19-22]. The observed variation of infection rate might be attributed to differences in study area, sample size, personal hygienic condition, and the socio-economic status as well as life style of persons contributing for risk of infection. Moreover, the difference in the sensitivity and specificity of employed stool antigen tests may also affect the detection rate of infection.

In our study, even though the agreement of $H$. pylori stool antigen and serum IgG detection is statistically significant, it is not strongly convincing [Cohen's Kappa $=0.271$, $p<0.0001$, 95\% CI: 0.191-0.351]. Serum IgG detection over estimates $H$. pylori infection (60.5\%) as compared to stool antigen detection which is similar to report of Alim et al. 69\% [24], Shimoyama et al. 61.4\% [28] and Balan et al. $35.8 \%$ [25]. The observed high seroprevalence of $H$. pylori infection in our study could be explained due to the following key facts: 1 ) It is clearly known that during $H$. pylori infection IgM is the first and early antibody to be produced [30], and later IgG develops [31], which remain with high titer and detectable indefinitely even after eradication of H. pylori. 2) Detection of IgG to H. pylori may not differentiate between current and past infection which leads to an overestimation of the prevalence [30]. Even though $H$. pylori stool antigen detection do not distinguish between live and dead bacteria, it is advantageous to detect early and specific exposure to the bacterium as compared to serology [32].

$H$. pylori feco-prevalence was not significantly associated with age, sex, residence, occupation and educational level $(p>0.05)$. Conflicting reports were documented between association of above mentioned factors and $H$. 
Table 3 Regression analysis of factors associated with feco-prevalence of $H$. pylori among symptomatic patients in Dessie Referral Hospital, Northeast Ethiopia, $2016(n=342)$

\begin{tabular}{|c|c|c|c|c|c|}
\hline Variable & Freq & $\mathrm{HpSA}(+)=\mathrm{no} / \%$ & $\operatorname{COR}(95 \% \mathrm{Cl})$ & $\mathrm{AOR}(95 \% \mathrm{Cl})$ & $p$-value \\
\hline \multicolumn{6}{|l|}{ Family size } \\
\hline$<4$ & 175 & $41(23.4)$ & ref & ref & \\
\hline$\geq 4$ & 167 & $63(37.7)$ & $1.98(1.24-3.17)$ & $1.83(1.10-3.05)$ & $0.020^{*}$ \\
\hline \multicolumn{6}{|l|}{ Hand washing after toilet } \\
\hline Yes & 322 & $94(29.2)$ & ref & ref & - \\
\hline No & 20 & $10(50.0)$ & $2.43(0.98-6.02)$ & $2.5(0.92-6.79)$ & 0.073 \\
\hline \multicolumn{6}{|c|}{ Eating raw fruit and vegetable } \\
\hline Never & 85 & $29(34.1)$ & ref & ref & \\
\hline At least once a day & 56 & $24(42.9)$ & $1.45(0.72-2.90)$ & $1.38(0.64-2.96)$ & 0.407 \\
\hline At least once a week & 201 & $51(25.4)$ & $0.66(0.38-1.14)$ & $0.64(0.35-1.18)$ & 0.151 \\
\hline \multicolumn{6}{|l|}{ Tea consumption } \\
\hline Yes & 232 & $65(28.0)$ & ref & - & - \\
\hline No & 110 & $39(35.5)$ & $1.41(0.87-2.29)$ & - & - \\
\hline \multicolumn{6}{|l|}{ Coffee consumption } \\
\hline Yes & 211 & $70(33.2)$ & ref & - & - \\
\hline No & 131 & $34(26.0)$ & $0.71(0.44-1.145)$ & - & - \\
\hline \multicolumn{6}{|l|}{ Alcohol drinking } \\
\hline Never & 183 & $48(26.2)$ & ref & ref & \\
\hline Once/week & 71 & $20(28.2)$ & $1.10(0.60-2.04)$ & $1.35(0.69-2.63)$ & 0.382 \\
\hline > once/week & 88 & $36(40.9)$ & $1.95(1.14-3.33)$ & $2.70(1.49-4.89)$ & $0.001^{*}$ \\
\hline \multicolumn{6}{|l|}{ ABO Blood group } \\
\hline Type A & 87 & $24(27.6)$ & $3.81(0.83-17.55)$ & $5.53(1.08-28.36)$ & $0.040^{*}$ \\
\hline Type B & 96 & $25(26.0)$ & $3.52(0.77-16.15)$ & $5.01(0.98-25.72)$ & 0.054 \\
\hline Type O & 137 & $53(38.7)$ & $6.31(1.42-28.1)$ & $8.93(1.79-44.48)$ & $0.008^{*}$ \\
\hline Type AB & 22 & $2(9.1)$ & ref & ref & \\
\hline \multicolumn{6}{|l|}{ Persons per room } \\
\hline 1 & 77 & $18(23.4)$ & ref & ref & \\
\hline 2 to 3 & 181 & $49(27.1)$ & $1.22(0.65-2.27)$ & $1.26(0.65-2.43)$ & 0.495 \\
\hline$>3$ & 84 & $37(44.0)$ & $2.58(1.31-5.10)$ & $2.91(1.39-6.11)$ & $0.005^{*}$ \\
\hline
\end{tabular}

Key: * Significant association Exist; $A O R$ adjusted odds ratio, $C O R$ crude odds ratio

pylori infection. The significant role of age for acquiring $H$. pylori infection was documented elsewhere [19], but it contrasts our result where no significant association was observed between age and H. pylori infection. Similarly, previous studies conducted in Ethiopia showed no significant association between age and $H$. pylori infection $[22,33]$. In the current study, there is no significant association between gender and $H$. pylori infection, which is in agreement with other previous studies that indicated no gender difference in $H$. pylori infection status $[19,33]$. However, some authors indicated that female [22] and male [21] were at higher risk of infection against their counter parts.

In our study, residence and marital status were not significantly associated with feco-prevalence. Previous reports in Ethiopia also showed no significant association with marital status [21, 22] and residence [21]. However, higher prevalence rate of $H$. pylori infection was observed among individuals living in rural and suburban area $[22,34]$, which differs from our result. This might be due to high number of (61.4\%) urban dwellers in our study. In our study, stool antigen detection also did not show any significant association with type of occupation which is in line with previous study in Ethiopia [22], but it contradicts to other study where agrarians were more affected [21]. This discrepancy could be due to the geographical as well as socio-economic differences, which may lead to occupational difference. Moreover, majority of our study participants were urban dwellers that are not involved in agricultural practice. Likewise, no statistically 
significant association was observed between $H$. pylori feco-prevalence and educational attainment, which is in agreement to other studies in Ethiopia [21, 22].

H. pylori feco-prevalence was significantly associated with large $(>3)$ family size and number of persons $(>3)$ sharing the same bed room in the household. This is similar to other findings where large family size significantly associated with H.pylori infection [21,34]. However, it differs from other study where no significant difference was detected with respect to family size [22]. This variation may be due to sample size difference. Moreover, factors contributing for the transmission of a bacterium may differ with geographical location and study population. Scholars also indicated that crowding condition is a risk for H. pylori infection [35] which could explain the observed significant association in this study.

This study also showed a significant association between $\mathrm{ABO}$ blood groups and stool antigen detection. Individuals with blood group type $\mathrm{O}$ were about nine times (Table 3 ) at higher risk of infection as compared to blood group type $\mathrm{AB}$, which is contrary to other studies that did not show any significant association [21, 22, 33, 34]. However, a stratified meta-analysis indicated that $\mathrm{O}$ blood group of dyspeptic patients were significantly associated with $H$. pylori infection [36]. The association of blood group type $\mathrm{O}$ and $H$. pylori infection could be related to the expression of carbohydrate receptors of $H$. pylori into gastric tissues in greater quantities among individuals with O blood group [37].

There are conflicting reports on the association between alcohol consumption and $H$. pylori infection. In Ethiopia, Kibru et al. [19] reported that alcohol consumption protects against $H$. pylori infection but Dilnessa et al. [22] showed no significant association in his report. Furthermore, frequent consumption of alcohol (>once/week) showed no significant association but less frequent consumption (<once/week) was protective [21]. In Germany, an inverse relationship was also documented between amount of alcohol consumption and $H$. pylori infection $[38,39]$ as moderate amount of alcohol consumption in the form of wine and beer protects against $H$. pylori infection [40]. However, the current study is in opposition to previously mentioned studies $[19,21,22,38-40]$ as frequent consumption of alcohol (>once/week) was significantly associated with feco-prevalence of $H$. pylori $(p=0.001)$. But our result is in line with previous report as large amount of alcohol consumption is positively associated with active $H$. pylori infection [41].

The reason for these contradictory results might be due to difference in types and amounts of consumed alcoholic beverages. In Ethiopia, common local alcoholic drinks are "Tella", "Teji" "Araki" and "beer" which are quite different in alcohol content. The significant association in our study could be explained due to the hypothesis that heavy alcohol consumption facilitates $H$. pylori infection by damaging the gastric mucosa. Besides the damaged gastric mucosa, bacterial adherence and host factors may also be involved in the synergistic effect for infection.

H. pylori stool antigen detection was not statistically associated with coffee consumption which is similar to previous reports from Ethiopia [22] and England [40], but differs from Germany where coffee consumption showed a positive dose response relation with active $H$. pylori infection [38]. This contradictory result might be due to variation in type, frequency as well as amount of daily consumed coffee which needs further study. In our study, smoking also did not show any significantly association with $H$. pylori feco-prevalence which is similar to other studies in Ethiopia and elsewhere [21, 22, 38]. This is possibly attributed to $H$. pylori eradication by increasing gastric acid secretion by smoking. Similarly, no significant association was observed between source of drinking water and $H$. pylori infection which is in line with previous studies in Ethiopia [21, 22]. In the current study, the observed lower contribution of source of water to $H$. pylori infection is probably due to type of study participants in which majority of them used pipe water for their daily consumption.

The current study showed no significant association between $H$. pylori infection and raw fruits and vegetables consumption which is in line with previous study [21]. No statistically significant association was also observed between tea consumption and $H$. pylori infection. Lack of association of above factors might be due to difference in types and amount of consumed tea, fruits and vegetables that may have different spectrum of antibacterial activity. Further analytical study designed to determine the effect of quantity and ingredient analysis is, therefore, warranted to document the real association of $H$. pylori infection, fruits, vegetables and tea consumption.

There are a few limitations of this study. The study population was only symptomatic patients presented to the hospital, which limits the actual prevalence of infections and do not totally reflect the number of infected individuals in the community. Besides cross-sectional, all information on life style factors was collected by a selfadministered questionnaire without determination of amount, types and biological markers. As compared to currently recommended stool antigen test (ELISA), relatively less sensitivity and specificity of the currently utilized test could underestimate and overestimate the burden of the disease respectively. Moreover, the small sample size may have an impact on the observed association variables, and thus, interpretations should be made cautiously.

\section{Conclusion}

The overall $H$. pylori stool antigen and anti-H. pylori $\operatorname{IgG}$ detection rate were 30.4 and $60.5 \%$ respectively. Even 
though statistically significant, the agreement between results of HpSA testing and IgG antibody serology was not strongly convincing. Feco-prevalence was significantly associated with overcrowding, alcohol consumption, and ABO blood group. However, no significant association observed between other sociodemographic variables, lifestyle factors and H.pylori stool antigen detection. Further studies with representative larger numbers of subjects should address the impact of life style factors such as smoking, and drinking practices particularly the type and amount of daily consumption of tea, coffee, alcoholic beverage; types of fruits and vegetables taken that might affect incidence of $H$. pylori infection.

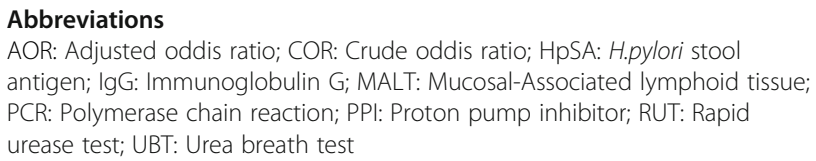
antigen; IgG: Immunoglobulin G; MALT: Mucosal-Associated lymphoid tissue; PCR: Polymerase chain reaction; PPI: Proton pump inhibitor; RUT: Rapid urease test; UBT: Urea breath test

\section{Acknowledgments}

The authors would like to express their gratitude to Wollo University for the financial support provided in the study. Likewise, we would like to acknowledge all the study participants who volunteered to give samples and respond to the questionnaire. Our special thanks goes to the Dessie Referral Hospital administration for their unreserved support during the data collection. Finally, we would like to thank Mr. Beju Ayele and Mr. Adugna Tesema who participated as data collector.

\section{Funding}

This study was supported by Wollo University. The funders had no role in study design, data collection and analysis, decision to publish, or preparation of the manuscript.

\section{Availability of data and materials}

The authors confirm that all data underlying the findings are fully available with corresponding author and within the manuscript. The underlying data cannot be shared publicly due to the presence of sensitive (confidential) participants' information. Corresponding author will be communicated if the need arises for further clarification of the findings under the manuscript.

\section{Authors' contributions}

AS is the principal investigator of the study and he performed the design of the study, data management, study supervision, analysis, interpretation of data and manuscript preparation. WD: involved in the designing, supervision, acquisition of data and critical review of the manuscript. Both authors read and approved the final manuscript for publication.

\section{Ethics approval and consent to participate}

The study was reviewed and approved by the Ethical Review Committee of the College of Medicine and Health Science, Wollo University. Permission to conduct the study was also obtained from the Hospital Administration. Written informed consent was obtained from each study participant (or their parent or legal guardian in the case of children under 18) before data collection and results were kept confidential. Any result that was necessary for the patient was communicated with the attending physician for appropriate management.

\section{Competing interests}

The authors declare that they have no competing interests.

\section{Publisher's Note}

Springer Nature remains neutral with regard to jurisdictional claims in published maps and institutional affiliations.
Received: 31 July 2017 Accepted: 30 May 2018

Published online: 07 June 2018

\section{References}

1. Olokoba A, Gashau W, Bwala S, Adamu A, Salawu FK. Helicobacter pylori infection in Nigerians with dyspepsia. Ghana Med J. 2013;47(2):79-81.

2. World Gastroenterology Organization Global Guideline. Helicobacter pylori in developing countries. WGO article. J Dig Dis. 2011;12:319-26.

3. Hunt RH, Xiao SD, Megraud F, et al. Helicobacter pylori in developing countries. World Gastroenterology Organization Global Guideline. J Gastrointestin Liver Dis. 2011:20:299-304.

4. Tanih NF, Ndip RN. A South African perspective on Helicobacter pylori: prevalence, epidemiology and antimicrobial chemotherapy, Review article. Afr J Microbiol Res. 2013;7(21):2430-7.

5. Ahmed KS, Khan AA, Ahmed I, et al. Prevalence study to elucidate the transmission pathways of Helicobacter pylori at oral and gastroduodenal sites of a South Indian population. Singap Med J. 2006;47(4):291-6.

6. Cover TL, Blaser MJ. Helicobacter pylori in health and disease. Gastroenterol. 2009;136:1863-73.

7. Sachs G, Scott DR, Wen Y. Gastric infection by Helicobacter pylori. Curr Gastroenterol Rep. 2011;13:540-6.

8. IARC monograph on the evaluation of carcinogenic risks to humans. Schistosomes, liver flukes and Helicobacter pylori. IARC. 1994;61:177-240.

9. Ferlay J, Shin HR, Bray F, et al. Estimates of worldwide burden of cancer in 2008: GLOBOCAN 2008. Int J Cancer. 2010;127:2893-917.

10. Pourakbari B, Ghazi M, Mahmoudi S, et al. Diagnosis of Helicobacter pylori infection by invasive and noninvasive tests. Braz J Microbiol. 2013;44:795-8.

11. Tonkic A, Tonkic M, Lehours P, Me'graud F. Epidemiology and diagnosis of Helicobacter pylori infection. Helicobacter. 2012;17 Suppl.1:1-8.

12. Di Rienzo TA, D'Angelo G, Ojetti V, et al. 13C-Urea breath test for the diagnosis of Helicobacter pylori infection. Eur Rev Med Pharmacol Sci. 2013; 17 Suppl.2:51-8.

13. Lopes Al, Vale FF, Oleastro M. Helicobacter pylori infection - recent developments in diagnosis. World J Gastroenterol. 2014;20(28):9299-313.

14. Ho B, Marshall BJ. Accurate diagnosis of Helicobacter pylori. Serologic testing. Gastroenterol Clin North Am. 2000;29(4):853-62.

15. Malfertheiner P, Megraud F, O'Morain CA, et al. Management of Helicobacter pylori infection-the Maastricht IV/ Florence Consensus Report. Gut. 2012;61: 646-64.

16. Calika Z, Karamesea M, Acara O, et al. Investigation of Helicobacter pylori antigen in stool samples of patients with upper gastrointestinal complaints. Braz J Microbiol. 2016;47:167-71.

17. Cirak MY, Akyön Y, Mégraud F. Diagnosis of Helicobacter pylori. Helicobacter. 2007;12(Suppl 1):4-9.

18. Gisbert JP, de la Morena F, Abraira V. Accuracy of monoclonal stool antigen test for the diagnosis of $H$. pylori infection: a systematic review and metaanalysis. Am J Gastroenterol. 2006;101:1921-30.

19. Kibru D, Gelaw B, Alemu A, Addis Z. Helicobacter pylori infection and its association with anemia among adult dyspeptic patients attending Butajira hospital, Ethiopia. BMC Infect Dis. 2014;14:656.

20. Gizachew T, Abebe H, Kassu D, Samuel E, Abate B. Association of dyspepsia symptoms and Helicobacter pylori infections in private higher clinic, Addis Ababa, Ethiopia. Ethiop Med J. 2011;49:109-16.

21. Hailu G, Desta K, Tadesse F. Prevalence and Risk Factors of Helicobacter pylori among Adults at Jinka Zonal Hospital, Debub Omo Zone, Southwest Ethiopia. Autoimmun Infec Dis. 2016; https://doi.org/10.16966/2470-1025.113

22. Dilnessa T, Amentie M. Prevalence of Helicobacter pylori and risk factors among dyspepsia and non-dyspepsia adults at Assosa General Hospital, West Ethiopia: a comparative study. Ethiop J Health Dev. 2017;31(1):4-12.

23. Wubejig A, Mulugeta K, Bayeh A. Prevalence and risk factors of $H$. pylori from dyspeptic patients in Northwest Ethiopia: a hospital based crosssectional study. Asian Pac J Cancer Prev. 2014;15(11):4459-63.

24. Alim A, Ataş M, Güneş T, Özkan S, Dündar N. Comparison of antigen and antibody detection tests used for diagnosing the Helicobacter pylori infection in symptomatic patients. Basic Clin Sci. 2010;1 (4):61-70.

25. Balan $\mathrm{K}$, Subbukesavaraja. Comparative study of noninvasive methods for diagnosis of Helicobacter Pylori in humans. Sch Acad J Biosci. 2013;1 (1):14-7.

26. Hassan MK, Haq M, Saifullah Z, Khan AG, Khattak AK, Khan AG. Frequency of Helicobacter pylori infection by testing stool antigen in patients with functional dyspepsia. Gomal J Med Sci. 2013;11:183-7. 
27. Buyukbaba-Boral O, Kucuker-Ang M, Aktas $\mathrm{G}$, Issever $\mathrm{H}$, Ang O. HpSA fecoprevalence in patients suspected to have $H$. pylori infection in Istanbul, Turkey. Int J Infect Dis. 2005;9(1):21-6.

28. Shimoyama T, Oyama T, Matsuzaka i, Danjo K, Nakaji S, Fukuda S. Comparison of a stool antigen test and serology for the diagnosis of Helicobacter pylori infection in mass survey. Helicobacter. 2009;14:87-90.

29. Talaaizadeh $\mathrm{AH}$, Borhani M, Moosavian M, et al. Prevalence of Helicobacter pylori infection detected by stool antigen test in Khuzestan Province, SouthWest of Iran from September to October 2009: a population-based study. Jundishapur J Microbiol. 2013;6(2):100-4.

30. Alem M, Alem N, Cohen $\mathrm{H}$, et al. Diagnostic value of detection of IgM antibodies to Helicobacter pylori. Exp Mol Pathol. 2002;72:77-83.

31. Fox JG, Megraud F; Helicobacter: In: Murray PR (ed). Manual of Clinical Microbiology 2009, 9th. 1, Ankara: American Society for Microbiology (ASM Press): $947-962$.

32. Krausse R, Múller G, Doniec M. Evaluation of a rapid new stool antigen test for diagnosis of Helicobacter pylori infection in adult patients. J Clin Microbiol. 2008;46(6):2062-5.

33. Milorad P, Vera A, Tanja I, et al. Relationship between Helicobacter pylori infection estimated by $14 \mathrm{C}$-urea breath test and gender, blood groups and Rhesus factor. Hell J Nucl Med. 2011;14(1):21-4.

34. Türkölmez S, Derya C, Füsun A, Meliha K. The relationship of Helicobacter pylori positivity with age, sex, and ABO/Rhesus Blood Groups in patients with gastrointestinal complaints in Turkey. Helicobacter. 2007;12:244-50.

35. Pandeya N, Whiteman DC. Prevalence and determinants of Helicobacter pylori sero-positivity in the Australian adult community. J Gastroenterol Hepatol. 2011;26:1283-9.

36. Shaweno D, Daka D. Association between O blood group and Helicobacter pylori infection: a systematic review and meta-analysis. J Public Heath Epidemiol. 2013;5(12):471-8.

37. Demattos LC. Histo-Blood Group carbohydrates and Helicobacter pylori infection J. Bacteriol Parasitol. 2012; https://doi.org/10.4172/2155- 9597. 1000e104.

38. Brenner H, Rothenbacher D, Bode G, Adler G. Relation of smoking and alcohol and coffee consumption to active Helicobacter pylori infection: cross sectional study. Br Med J. 1997;315:1489-92.

39. Brenner H, Rothenbacher D, Bode G, Adler G. Inverse graded relationship between alcohol consumption and active infection with Helicobacter pylori. Am J Epidemiol. 1999:149:571-6.

40. Murray LJ, Lane AJ, Harvey IM, Donovan JL, Nair P, Harvey RF. Inverse relationship between alcohol consumption and active Helicobacter pylori infection: the Bristol Helicobacter Project. Am J Gastroenterol. 2002;97(11): 2750-5.

41. Zhang L, Eslick GD, Xia HHX, Wu C, Phung N, Talley NJ. Relationship between alcohol consumption and active Helicobacter pylori infection. Alcohol Alcoholism. 2010:45(1):89-94.

\section{Ready to submit your research? Choose BMC and benefit from:}

- fast, convenient online submission

- thorough peer review by experienced researchers in your field

- rapid publication on acceptance

- support for research data, including large and complex data types

- gold Open Access which fosters wider collaboration and increased citations - maximum visibility for your research: over $100 \mathrm{M}$ website views per year

At BMC, research is always in progress.

Learn more biomedcentral.com/submissions 